\title{
Salt removal from soil during rainy season of semi-arid climate following an assumed salt accumulation from previous cultivations fertilized with urine
}

\author{
Mokhtar Guizani $^{1}$ (D) Takahisa Fujii $^{2} \cdot$ Nowaki Hijikata $^{1} \cdot$ Naoyuki Funamizu $^{1}$
}

Received: 4 February 2016/ Accepted: 18 November 2016/Published online: 29 November 2016

(C) Springer International Publishing Switzerland 2016

\begin{abstract}
Due to its high salt content, urine use as a fertilizer threatens agricultural land by causing soil sodification, especially in arid and semi-arid lands where limited water resources restrict full salt washout. This study investigated the management of salt accumulation in a soil in which urine was assumed to be previously directly applied as a fertilizer. Since feasibility studies of urine use as a fertilizer have been previously reported in the arid land of Burkina Faso in the Sahel region, we investigated the removal during rainy season using rainfall and evaporation data from Burkina Faso of the salts accumulated in the soil from previous cultivations assumed to be fertilized with urine. Column test experiments were carried out under greenhouse conditions. The experiment involved irrigation of planted and non-planted pots for 56 days with de-ionized water to reproduce the rainy season in Burkina Faso. Prior to the experiments, $400 \mathrm{mg} /$ pot of $\mathrm{NaHCO}_{3}$ was added to the top $10 \mathrm{~cm}$ of the soil columns, simulating the initial salt content in the soil due to the assumed previous irrigation using urine $(\mathrm{pH}=7.63)$. Although, Na salts are the dominant salt in urine, sodium bi-carbonate has been used in this study as it has a buffering capacity to resist to sudden $\mathrm{pH}$ changes. The experimental study revealed that a significant portion of salt that accumulated in the column during cultivation is washed out of non-planted pots during the rainy season. In planted pots, the higher evaporation rate led to less washout and more salt accumulation in the
\end{abstract}

Mokhtar Guizani

g_mokh@yahoo.fr; mguizani@eng.hokudai.ac.jp

1 Environmental Engineering Division, Faculty of Engineering, Hokkaido University, Kita 13 Nishi 8, Sapporo, Japan

2 Graduate School of Engineering, Hokkaido University, Kita 13 Nishi 8, Sapporo, Japan soil. Of the original $400 \mathrm{mg} /$ pot, $259 \mathrm{mg} /$ pot was washed out of non-planted pots, while only $80 \mathrm{mg} /$ pot was washed out of planted pots. Another $40 \mathrm{mg} /$ pot was taken up by plants in the case of planted pots. A HYDRUS-1D model was then used to predict the fate of the salts in the soil (non-planted) under different conditions (e.g., variable calcium supply, variable initial Na concentration). Model calibration was performed using data from previous experiments. The application of $\mathrm{Ca}$ promoted lower sodic conditions in the soil. A Ca application of $14 \mathrm{~g} / \mathrm{m}^{2}$ is required to free all the remaining sodium salts via the cation exchange mechanism allowing their full washout from the soil.

Keywords Urine - Sodium salts · Washout · Plant uptake

\section{Introduction}

The demand for nitrogen, phosphorus and potassium (NPK) fertilizers will continue to increase in coming years as a result of population and economic growth (FAO 2008). Higher demand results in higher prices for fertilizers (FAO 2009; Cordell et al. 2009), which in turn is likely to reduce agricultural productivity leading to food insecurity. Lowincome countries, such as sub-Saharan countries, are the most vulnerable to fertilizer scarcity. Due to its high cost and their limited purchasing power, sub-Saharan farmers have limited access to fertilizers, inhibiting their efforts to improve soil fertility and agricultural productivity. A report published by the FAO (2010) regarding food insecurity around the world stated that the proportion of undernourished individuals in sub-Sahara African countries reached $30 \%$ in 2010. In an attempt to find an affordable and accessible substitute for industrial fertilizers, human urine 
has exhibited considerable promise and has distinct advantages. Human urine is rich in mineral compounds and has a relatively low sanitary risk. It contains $80 \%$ of the nitrogen $(\mathrm{N}), 55 \%$ of the phosphorus $(\mathrm{P})$ and $60 \%$ of the potassium $(\mathrm{K})$ found in domestic wastewater (Kirchmann and Pettersson 1995; Jönsson et al. 2000; Mnkeni et al. 2005, 2008). Historically, plant fertilization using human urine has been practiced in some parts of Asia since ancient times, as reported by Nettling (1993) and Goldstein (2012). Interest in the fertilizer value of human urine and its application to agricultural practices has become more common and has attracted researcher interest from around the world. Interestingly, many sub-Saharan countries, including Burkina Faso, are now considering the use of urine to improve soil fertility. Studies by Ushijima et al. (2015) and Funamizu (2009) aimed to promote resourceoriented sanitation concepts as a route for mitigating water demand and recycling nutrients while promoting agrobusiness models and ecologically sound sanitation in Burkina Faso. Urine diverting toilets and collection systems have been previously developed to collect urine. Sene (2013) focused on urine as a liquid agricultural fertilizer in Burkina Faso. A similar study was performed by Andersson (2015), who used human urine to enrich soils for sustainable food production in Uganda.

Although, human urine used as a fertilizer is a good source of nitrogen, it contains some harmful substances such as salts, which may harm the soil (soil sodification due to a high sodium level) and have adverse effects on plant growth and nutrient uptake. Sodium chloride is one of the most predominant salts found in urine. The average concentration of sodium $(\mathrm{Na})$ in undiluted, fresh human urine is estimated to be $0.94-0.98 \mathrm{~g} / \mathrm{L}$ (Kirchmann and Pettersson 1995), while a value of $2.34 \mathrm{~g} / \mathrm{L}$ of sodium content in urine was recently reported in the literature (Pradhan et al. 2010). Dagerskog and Bonzi (2010) reported sodium contents in source-separated urine ranging from 2.9 to $3.5 \mathrm{~g} / \mathrm{L}$. Sene et al. (2013a) used an average value of $2.84 \mathrm{~g} / \mathrm{L}$ for synthetic urine preparation and this value was adopted in this paper. Consequently, applications of human urine as a liquid fertilizer may result in the potential accumulation of sodium ( $\mathrm{Na}$ ) ions in soil and eventually be detrimental to plant growth and production, especially in dry areas where urine may be reused at several-year intervals. Moreover, it has been previously reported that salts, including sodium and chlorides, may be toxic to plants and inhibit their growth (Holliman 1998). Consequently, there is growing concern regarding the toxicity of human urine (Höglund 2001).

Studies such as Adrover et al. (2012), Dikinya and Areola (2010) and Johantigh (2008) reported that prolonged use of recycled wastewater for irrigation increased salinity in the soil. The risk of increased salt content in the vadose zone following urine application on farmland is also a concern, as urine is rich in sodium chloride salts. Sene et al. (2012) investigated the direct use of urine in the Sahel region of Burkina Faso and determined the urine amounts that must be applied to Komatsuna (Brassica rapa) to meet the plants' nitrogen and phosphorus needs. In addition, Hijikata et al. (2014) monitored salt accumulation in gardens fertilized with urine and concluded that salt accumulation in the soil during the dry season is a major concern. However, no studies have been reported regarding the management of accumulated salts in the soil and their removal following urine use as an agricultural fertilizer.

Alternatives for salt removal from soils include leaching using sufficient irrigation, or phytoremediation using halophytes and moderately halophytic plants (Qadir et al. 2005). In water scarce countries, such as in Burkina Faso, farmers do not have access to sufficient water resources or appropriate irrigation systems. Therefore, we assume that salts accumulated in the soil following urine use as a fertilizer can be washed away during the rainy season or absorbed by moderately halophytic plants as a sort of phytoremediation. Inoue (2012) lists useful salt tolerant plants that can absorb sodium salts and produce a harvest. This list includes sorghum, a staple plant in many arid lands such as in Burkina Faso, among others. Hence, we assume that sorghum is a moderately halophytic plant that can serve as cleanup crop. However, evapotranspiration is the predominant factor leading to the accumulation of salts in agricultural soils, as this process removes water from the soil, leaving most of the salt behind and increasing the salts concentrations in the remaining soil water (Corwin et al. 2007; Gonçalves et al. 2006). In this regard, this investigation will include a comparison between planted and nonplanted pots.

Furthermore, it is well known that in presence of high sodium salts in the soil it is a common practice to apply soluble calcium (e.g., gypsum) to the soil to replace sodium cations by calcium cations and the leach the sodium out. However, sandy soils does not contain appreciable amounts of calcium (Tanaka 2005). In addition, small-scale farmers in Burkina Faso cannot afford to apply gypsum to their soils and we assume that small-scale farmers can alternatively use calcium rich ash from their cook stoves. Indeed, in a study on ashes derived from the combustion of different varieties of wood biomass, Vassilev et al. (2010) reported that wood and woody biomass ashes are calcium rich.

Therefore, the overall objective of this paper is to investigate the management of salt accumulation in a soil to which urine was assumed to be previously directly applied as a liquid fertilizer. We focus on the salt removal during rainy season using rainfall and evaporation data from Burkina Faso in Sahel region, where studies on the 
feasibility of urine as a fertilizer have been reported. First, we evaluate the salt washout during the rainy season in sorghum-planted and non-planted soils. Then, the effects of the initial salt concentration in the soil and the calcium supply on salt removal are evaluated and discussed. In this study, an experimental column investigation was carried out, followed by a model simulation using HYDRUS-1D software to predict the fates of salts. Based on the results of this study, we deduce the maximum amount of urine that can be applied during the dry season without accumulating salt in the soil. Although this study reports an interesting laboratory experimental and numerical simulation findings on fate of salts accumulated in the soil from previous irrigation using urine as liquid fertilizer, the current finding cannot be transposed directly to the use of urine in real soil in the dry land. Further investigations will be required.

\section{Materials and methods}

\section{Approach and general study information}

A pot experiment was conducted under controlled conditions followed by numerical simulations representing different scenarios using a HYDRUS-1D model. The pot experiment assesses the rainy season washout of previously accumulated salts following the assumed urine application as a fertilizer during the cultivation season in planted and non-planted pots. In addition, pot experiment data are used to calibrate the model. Rainfall data from Burkina Faso, located in sub-Saharan Africa, where used to assess the effect of salt washout during rainy season in both experimental pots and numerical model. The climate of Burkina Faso is tropical, with a rainy season (May-September) and dry season (the rest of the year). During the rainy season, the country receives between 4 and $6 \mathrm{~mm} /$ day.

\section{Pot experiment}

A soil column experiment was conducted inside the greenhouse at Hokkaido University $\left(43^{\circ} 04^{\prime} 11.6^{\prime \prime} \mathrm{N}, 141^{\circ}\right.$ $20^{\prime} 22.4^{\prime \prime}$ E) from July 2014 to September 2014. The temperature and relative humidity in the greenhouse during the experimental period ranged from 13 to $51{ }^{\circ} \mathrm{C}$ and from 24 to $95 \%$, respectively.

The experiment was conducted using $90 \mathrm{~cm}$ long columns with $15-\mathrm{cm}$ diameters. Twelve Sorghum planted pots and four non-planted (control) pots were prepared. A schematic diagram of the experiment is shown in Fig. 1. All pots were packed with sandy soil composed of a mixture of commercially available sand (known as silica sand present in a crystalline form of quartz) and kaolinite at a ratio of 1:5. Because the sandy soil has poor water retention and low cation exchange capacity (CEC), kaolinite is added to improve the CEC and increase the potential of the soil to retain plant nutrients and water. The pots were divided into intervals of $0-5,5-10,10-30,30-50$ and $50-70 \mathrm{~cm}$ as a vadose zone for subsequent analysis. The final depth of 70-90 cm was a saturated zone. The soil used in this experiments has a dry bulk density of $1.5 \mathrm{~g} /$ $\mathrm{cm}^{3}$.

In the upper layer $(0-10 \mathrm{~cm}), 400 \mathrm{mg} /$ pot of $\mathrm{NaHCO}_{3}$ was added to the soil, simulating the initial salt content that existed in the soil due to the assumed previous irrigation using urine $(\mathrm{pH}=7.63)$. Although $\mathrm{NaCl}$ is the most dominant salt in urine, this choice will not affect the results. It is worth mentioning that sodium bicarbonate $\left(\mathrm{NaHCO}_{3}\right)$ has been used in this experiment as it offers a good buffering capacity to limit sudden changes of $\mathrm{pH}$. It is worth mentioning that no significant variation in the $\mathrm{pH}$ was recorded during experiments. At the beginning of the experiment and prior to the salt addition in the upper layer, the soil was saturated with $3 \mathrm{~L}$ of de-ionized water to wet the soil for planting. Then, the experiment involved $6 \mathrm{~mm}$ daily $(100 \mathrm{~mL})$ drip irrigation using distilled water, simulating the rainy season in Burkina Faso. On the 4th and 29th days, an $80 \mathrm{~mL}$ Hoagland solution was applied to supply nutrients to each plant.

Polyvinyl tubing was connected to the bottom of each pot and leachate samples were collected weekly. The sample weights were determined using an electronic balance (OHAUS). The Na concentration in the leachate was determined using a Multitype ICP Emission Spectrometer ICP-AES (ICPE 9000, Shimadzu) after filtration through a $0.45-\mu \mathrm{m}$ pore filter (ADVANTEC). The total amount of leached sodium salts was then calculated.

Moreover, one control pot and three planted pots were broken every two weeks for subsequent soil and plant analyses. The soil samples collected from each layer were vigorously mixed and then measured and analyzed. The water contents of soil samples were analyzed using the gravimetric method, and samples were dried in an oven at $105{ }^{\circ} \mathrm{C}$ for $24 \mathrm{~h}$ (Shukla et al. 2014).

Soil water content, leachate and salt concentration measurements were used to calibrate the water flow and solute transport processes in the HYDRUS-1D software package with no water or osmotic stress.

Sorghum plants were sampled every two weeks from their respective pots. They were then dissected for further analysis. Plant roots, stalks and tillers were sampled, washed and dried at $60{ }^{\circ} \mathrm{C}$ for 5 days. Dried plants $(25 \mathrm{~g})$ were ground using a mortar and pestle. Then, distilled water was added to the ground roots, stalks and tillers following their digestion by nitrate and hydrogen peroxide at $140{ }^{\circ} \mathrm{C}$ and mixed vigorously. The mixture was centrifuged for $5 \mathrm{~min}$ at $5000 \mathrm{rpm}$. Supernatant was collected 
Fig. 1 Schematic diagram of the experiment

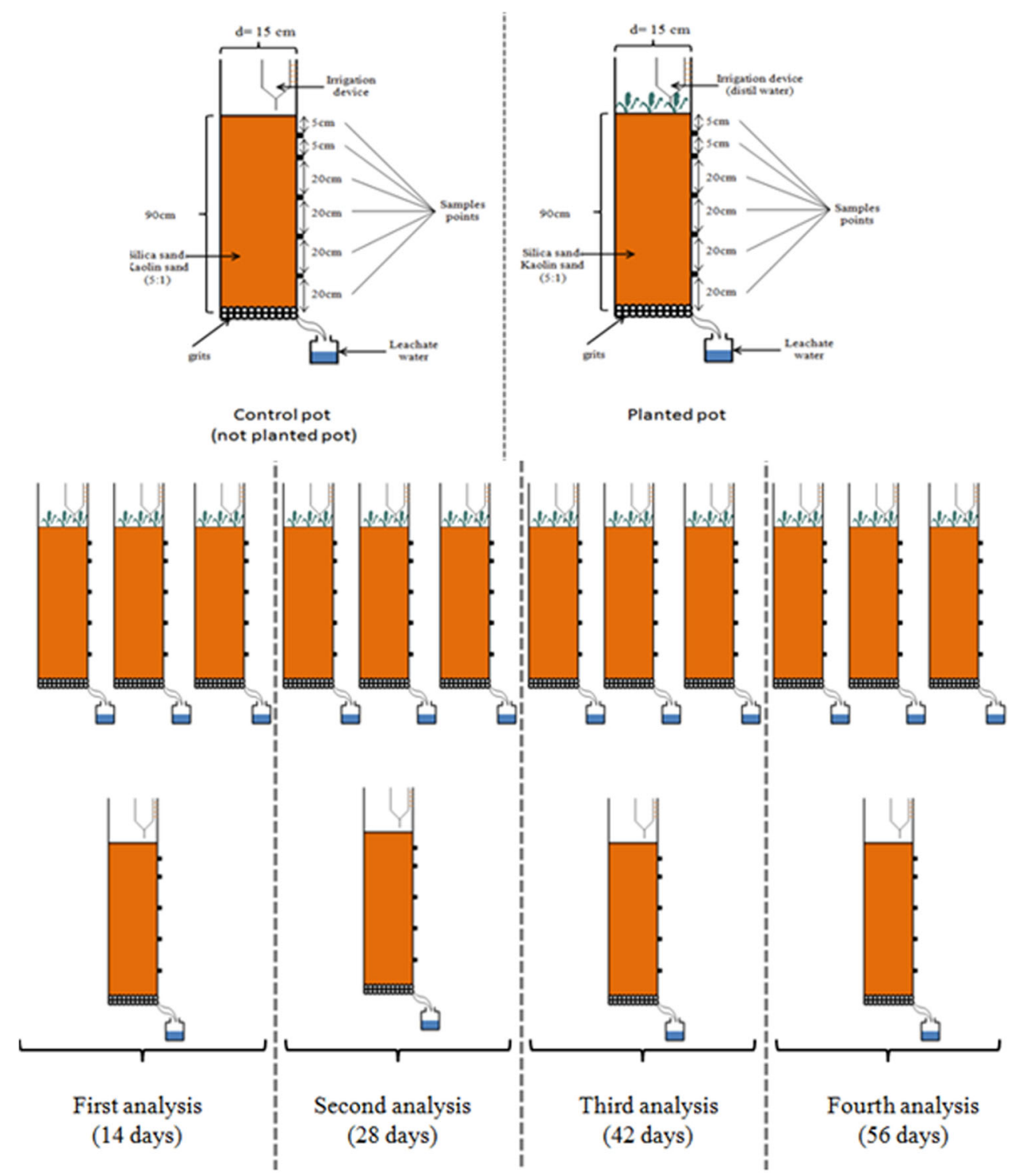

and filtered through a $0.45-\mu \mathrm{m}$ pore filter (ADVANTEC). The sodium salt concentration in the filtrate (diluted as necessary) was determined using an ICP-AES in the same manner employed to determine the leachate (ICPE 9000, Shimadzu). The total sodium salt uptake by the plant was then calculated.

\section{HYDRUS-1D simulations}

The major ion chemistry module UNSATCHEM in HYDRUS-1D (Šimunek et al. 2008) was used to simulate the water content and the salt movement in the soil. All of the simulations were conducted in non-planted pots, meaning that the effects of rainy season additions of calcium on $\mathrm{Na}$ removal were predicted. First, simulations were performed to tune the model and reproduce experimental findings in terms of the leachate volume and sodium salt removal. After the model was calibrated, different scenarios were simulated. The first simulation investigated the removal of $\mathrm{Na}$ that accumulated in the soil due to previous cultivations. The second simulation investigated the effect of the calcium supply on the sodium salt removal. Table 1 summarizes the cases simulated.

The measured results from pots experiments were used to calibrate the HYDRUS-1D model and predict the soil water contents, leachate and salt $\left(\mathrm{Na}^{+}\right)$concentrations in the soil and in the leachate. The calculations of water and $\mathrm{Na}^{+}$were based on the HYDRUS-1D predictions for the whole simulation period. The software helped us to understand the effects of the rainy season and the $\mathrm{Ca}^{2+}$ addition on the removal of $\mathrm{Na}^{+}$from the soil to determine a safe urine application level without deteriorating the soil. 
Table 1 Simulation cases and conditions

\begin{tabular}{llll}
\hline Sim & $\begin{array}{l}\text { Na input } \\
\left(\mathrm{g} / \mathrm{m}^{2}\right)\end{array}$ & $\begin{array}{l}\text { Ca supply } \\
\left(\mathrm{g} / \mathrm{m}^{2}\right)\end{array}$ & $\begin{array}{l}\text { Simulation conditions } \\
\text { Rainfall and evaporation } \\
\text { data obtained from }\end{array}$ \\
\hline $\begin{array}{l}\text { Run 1 (model } \\
\text { calibration) } \\
\text { Run 2 }\end{array}$ & 22.6 & 45.2 & Pot experiment \\
Run 3 & 6.95 & 0 & $\begin{array}{c}\text { Burkina Faso rainfall and } \\
\text { evaporation data } \\
\text { Burkina Faso rainfall and } \\
\text { evaporation data } \\
\text { Burkina Faso rainfall and } \\
\text { evaporation data }\end{array}$ \\
\hline
\end{tabular}

\section{Model calibration and validation}

For a successful use of the HYDRUS-1D model, several input parameters (e.g., soil hydraulic parameters, solute transport and reaction parameters, etc.) and boundary conditions need to be calibrated (Šimůnek and Hopmans 2009). Some parameters such as soil water retention parameters $\left(\theta_{\mathrm{r}}\right.$ and $\left.\theta_{\mathrm{s}}\right)$ were obtained from laboratory-determined soil water retention curves using suction tables. Soil bulk density was also measured in the lab by the determination of dry weight of a given volume of soil (McKenzie et al. 2002). Other parameters were estimated using HYDRUS-1D model in a process called model calibration. They were manipulated, within reasonable ranges, until the simulated model results approach closely the observed variables. The objective function to be minimized during the parameters estimation might present several local minimums (Šimůnek and Hopmans 2009). Thus, and to overcome this issue, we performed minimization problem several times using different initial estimates. The values that minimized the root mean square error (RMSE) index between the measured and simulated values of the leachate, water storage and sodium salt concentrations (Chu and Shirmohammadi 2004; Singh et al. 2004; Vazquez-Amábile and Engel 2005) were selected. The obtained parameters such as hydraulic conductivity $\left(K_{\mathrm{s}}\right)$ and the empirical parameters $\alpha$ and $n$ and solute and reaction parameters were verified to be comparable to values reported in the literature. After calibration, model was validated with a new set of data. Anderson and Woessner (1991) states that the model is validated if it predicts the system response within acceptable limits.

\section{HYDRUS-1D model input data}

\section{Initial conditions and soil properties}

The initial soil water content was set to a uniform value of $0.25 \mathrm{~cm}^{3} / \mathrm{cm}^{3}$ throughout the soil profiles by supplying $3 \mathrm{~L}$
Table 2 Physical and chemical soil characteristics (initial conditions)

\begin{tabular}{ll}
\hline Parameters & Values \\
\hline Depth $(\mathrm{cm})$ & $0-90$ \\
Bulk density $(\mathrm{g} / \mathrm{kg})$ & 1.5 \\
$\mathrm{EC}(\mathrm{ds} / \mathrm{m})$ & 0.63 \\
$\mathrm{SAR}(\mathrm{mmol} / \mathrm{L})^{1 / 2}$ & 0.5 \\
$\mathrm{pH}$ & 7 \\
$\mathrm{Soluble}^{+}$cations $(\mathrm{mmol} / \mathrm{L})$ & \\
$\mathrm{Na}^{+}$ & 1.52 \\
$\mathrm{Ca}^{2+}$ & 0.64 \\
$\mathrm{Mg}^{2+}$ & 0.64 \\
$\mathrm{~K}^{+}$ & 0.235 \\
$\mathrm{Exchangeable} \mathrm{cations}(\mathrm{mmol} / \mathrm{kg})$ & \\
$\mathrm{Na}{ }^{+}$ & 71.07 \\
$\mathrm{Ca}$ & \\
$\mathrm{Mg}^{2+}$ & 10.72 \\
$\mathrm{~K}^{+}$ & 1.1 \\
$\mathrm{CEC}$ & 3.63 \\
$\mathrm{Gapon} \mathrm{selectivity} \mathrm{coefficient}(\mathrm{mmol} / \mathrm{L})^{-1 / 2}$ & 86.52 \\
$\mathrm{KCa} / \mathrm{Na}$ & \\
$\mathrm{KMg} / \mathrm{Ca}$ & 1.51 \\
$\mathrm{KCa} / \mathrm{K}$ & 0.23 \\
\hline
\end{tabular}

of distilled water to the column prior to the experiment and prior to sodium salt addition in the upper layer $(0-10 \mathrm{~cm})$. Initial conditions for the UNSATCHEM module were given in terms of concentrations of $\mathrm{Na}^{+}, \mathrm{Ca}^{2+}, \mathrm{Mg}^{+}$and $\mathrm{K}^{+}$in the liquid and solid phases. To obtain these values, chemical analyses were performed on soil samples collected at the beginning of the experiments. Exchangeable cations were also determined. Following the chemical analyses performed on soil samples collected from the soil columns, the physical and chemical characteristics of the soil were obtained (soil parameters, soluble cations, exchangeable cations and Gapon selectivity coefficients). These findings are summarized in Table 2.

\section{Boundary conditions}

Atmospheric and free drainage boundary conditions were defined at the surface and at the bottom of each pot. Atmospheric boundary conditions were specified using daily values of irrigation and evapotranspiration. As required by HYDRUS-1D, evapotranspiration is divided into plant transpiration and soil evaporation and is estimated as a function of the soil cover factor and leaf area index (Ritchie 1972). However, in this paper, we only simulated non-planted pots. Hence, only evaporation is considered. In the pot experiment, the evaporation values 
Table 3 Atmospheric (irrigation and evapotranspiration) data for simulations

\begin{tabular}{llllll}
\hline Study period & Pot experiment & & \multicolumn{2}{l}{ Burkina Faso meteorological conditions } \\
\cline { 2 - 3 } & Rainfall $(\mathrm{mm})$ & Evaporation $(\mathrm{mm})$ & & Rainfall $(\mathrm{mm})$ & Evaporation $(\mathrm{mm})$ \\
\hline July (0-28 days) & $6(4 \mathrm{~mm}$ on the 4th day) & Obtained from the water & 5.8 & 4.6 \\
August (29-56 days) & $6(4 \mathrm{~mm}$ on the 29th day) & balance (see Fig. 2) & 7.3 & 4.4 \\
\hline
\end{tabular}

were deduced from the water balance. In the model simulation based on Burkina Faso conditions, the evaporation values and irrigation values were obtained from meteorological data. Daily values of irrigation and evaporation (for both the pot experiment and Burkina Faso meteorological data) spanned the 56-day simulation period, which lasted from July to September, as shown in Table 3. On days four and 29, a Hoagland solution (reagent-based fertilizer rich in calcium) was added, supplying 480, 496 and $896 \mathrm{mg} \mathrm{K} /$ pot to ensure a normal plant growth without nutrient deficiency.

During the rainy season in Burkina Faso, approximately $6 \mathrm{~mm}$ falls each day. Hence, irrigation is set to $6 \mathrm{~mm} /$ day except for on day 4 and day 29 , when only $4 \mathrm{~mm} /$ day of distilled water was applied. However, evapotranspiration input data for the model were estimated from planted and non-planted pots based on experimental measurements. Evapotranspiration data from planted pots are shown in Fig. 2.

\section{Results and discussion}

\section{Effects of the cleaning crop and leaching}

Figure 3 illustrates the total leachate volume results during the 8 weeks for both control and planted pots. In this figure, the leachate volumes in control pots increased

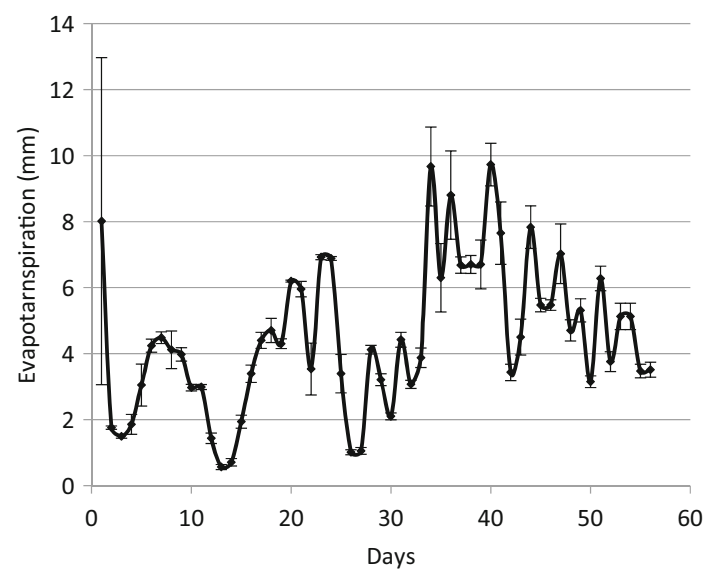

Fig. 2 Daily values of evaporation in non-planted pots (deduced from the water balance in the pot experiment)

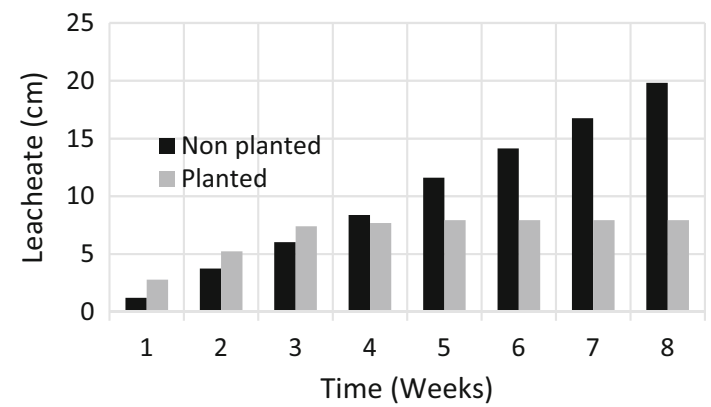

Fig. 3 Total leachate volumes in control and planted pots

constantly. In planted pots, the leachate increased during the first 3 weeks. However, no leachate is observed after 4 weeks. Therefore, higher leachate was observed in control pots in comparison with the planted pots case. This is explained by the fact that the plant takes up more water after the development of roots and leaves.

US Salinity Laboratory Staff (1954) formally introduced the leaching fraction to calculate the salt build up in the soil. It represents the fraction of water above what the plant needs. It equals the volume of leachate divided by the amount of applied water. Because the initial existing salt contents are known $\left(22.6 \mathrm{~g} / \mathrm{m}^{2}\right)$ and the salts removed by leachate and/or plant uptake are deduced from experimental measurements, stored salts in the soil can be obtained. Figure 4 illustrates the salt removal in both planted and non-planted pots. The salt uptake factor (UF) by green sorghum was estimated by measuring the ratio of sodium ions in the plant to the sodium ions in the soil. An uptake factor of 0.6 was recorded. Being less than one, the uptake factor indicates that the sodium ions are excluded by the plant and not accumulated. Indeed, the low proportion of sodium ions in the plant confirms the negative selectivity of these unnecessary ions by grain sorghum as reported in the literature. Moreover, although sorghum has adsorbed some salts, non-planted pots exhibited better removal. In control pots, the removal amount continuously increased due to the increased leachate volume. However, in planted pots, the removal amount increased very little after 4 weeks. This is because after 4 weeks, there is no leachate. In addition, the removal by plant uptake was smaller than that by leachate. Therefore, washout by rainfall may be more efficient than cleanup crops during the rainy season. In brief, almost all $\mathrm{Na}$ salts applied in control pots exhibited less than $70 \mathrm{~cm}$ of leaching. In planted pots, 
Fig. 4 Sodium salt removal from pots

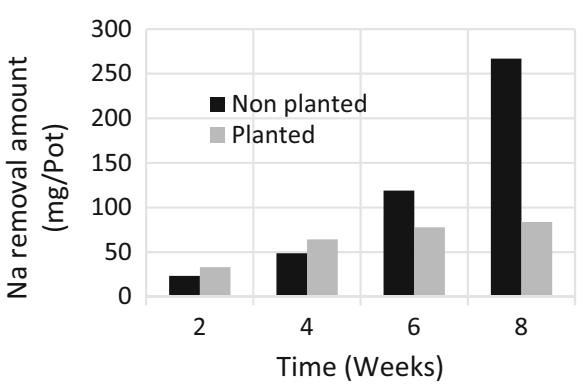

(a) Salt removal in planted and non-planted columns

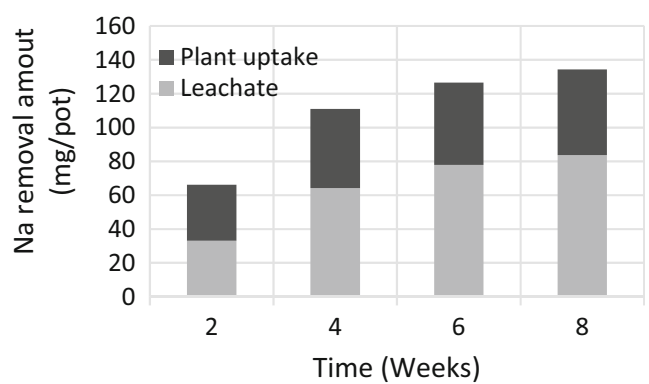

(b) Salt washout and plant salt uptake in planted pots significant amounts of the applied salts remained in the soil column. These findings confirm that evapotranspiration is a predominant factor, and water is removed from soil while salts are left behind. In addition, phytoremediation did not exhibit good results because sorghum is not a good halophyte plant. Therefore, based on these results, salt washout can be expected in bare soils during the rainy season, while sorghum-planted soils will accumulate salt.

\section{HYDRUS-1D model calibration and simulation results}

The experimental results illustrated above (i.e., leachate and water storage in control pots) were used to calibrate and tune the HYDRUS-1D model for the further water flow simulations. Soil samples were collected from plots at the beginning of the experiment to measure hydraulic soil properties. The soil water retention parameters $\left(\theta_{\mathrm{r}}\right.$ and $\left.\theta_{\mathrm{s}}\right)$ were obtained from laboratory tests, as explained above. The van Genuchten-Mualem parameters were calibrated by trial and error methods. Root mean square error was used as a statistical index to evaluate the level of agreement between measured data and simulated results (e.g., water leachate, water storage/content and salt concentration). The obtained parameters were verified with data from the literature. Tables 4 and 5 show the van Genuchten-Mualem hydraulic soil parameters and solute transport and reaction parameters calibrated based on the pot experimental results and/or measured in the lab. Table 6 shows the RMSE values between observation and simulation values when the tuned parameters were retained.

Following this calibration, the model adequately reproduced the experimental data, as shown in Fig. 5. Dots show the experimental results, and simulation parameters were fit to experimental results. Additionally, the lines show the simulation results. Because the model reproduces the experimental data well, it is concluded that the HYDRUS1D model can successfully simulate water and salt transport in the soil. Therefore, after successful calibration of HYDRUS-1D, simulations were carried out to analyze the
Table 4 van Genuchten-Mualem hydraulic soil parameters

\begin{tabular}{llllll}
\hline$\theta_{\mathrm{r}}\left(\mathrm{cm}^{3} / \mathrm{cm}^{3}\right)$ & $\theta_{\mathrm{s}}\left(\mathrm{cm}^{3} / \mathrm{cm}^{3}\right)$ & $\alpha\left(\mathrm{cm}^{-1}\right)$ & $n(-)$ & $K_{\mathrm{s}}(\mathrm{cm} /$ day $)$ & $l(-)$ \\
\hline 0 & 0.3 & 0.075 & 1.2 & 90 & 0.5 \\
\hline
\end{tabular}

fate of sodium salts in a soil column (non-planted) under different scenarios. These scenarios include evaluation of sodium salt removal under the rainfall and evaporation data from Burkina Faso. The effect of the amount of sodium salts initially present in the soil on salt removal from the soil due to salt accumulation from previous cultivations using urine was also evaluated. Finally, the effect of calcium supply on sodium salt removal was investigated. In terms of these simulations, the acceptable amount of urine that can be applied to farmland can be obtained.

\section{Simulation of Na salts removal}

Removal of $\mathrm{Na}$ that accumulated in the soil from previous cultivations was assessed using the HYDRUS-1D model. The simulation considered the case of the precipitation and evaporation data in the Sahel region of Burkina Faso during the rainy season. Precipitation and evaporation data for this climate are given in Table 3. In a former study reported by Sene et al. (2013a), three successive cultivations of Komatsuna (Brassica rapa) fertilized with human an excessive urine volume led to an accumulation of up to $699.93 \mathrm{mg} /$ pot of sodium. Taking into account the size of pots used, the accumulated salts expressed in terms of area density also known as mass of salts per unit area is in the order of $6.95 \mathrm{~g} / \mathrm{m}^{2}$ of sodium salts in the soil before the start of the rainy season. Therefore, in this simulation, we considered an initial salt amount of $6.95 \mathrm{~g} / \mathrm{m}^{2}$ in the upper layer of the soil column (the upper $10 \mathrm{~cm}$ ). Salt removal (washout) as a function of time is shown in Fig. 6. Note that after 4 weeks, the removal rate increased. Indeed, during the second period (from week 4 to 8 ), the meteorological conditions are more favorable than in the first 
Table 5 Solute transport and reaction parameters

\begin{tabular}{llllll}
\hline Bulk d $\left(\mathrm{g} / \mathrm{cm}^{3}\right)$ & $D_{\mathrm{w}}\left(\mathrm{m}^{2} / \mathrm{s}\right)$ & Disper $(\mathrm{cm})$ & Calc.SA $\left(\mathrm{m}^{2} / \mathrm{dm}^{3}\right)$ & Dolom.SA $\left(\mathrm{m}^{2} / \mathrm{dm}^{3}\right)$ & DOC $\left(\mathrm{mmol} / \mathrm{dm}^{3}\right)$ \\
\hline 1.49 & 5.6 & 25 & 0 & 0 & 0 \\
\hline
\end{tabular}

Bulk $d$ bulk density, $D_{\mathrm{w}}$ molecular diffusion coefficient in free water, $D_{\mathrm{d}}\left(\mathrm{m}^{2} / \mathrm{s}\right)$, Disper longitudinal dispersity $(\mathrm{cm}), C E C$ cation exchange capacity, CEC (meq/kg), Calc.SA calcite surface area $\left(\mathrm{m}^{2} / \mathrm{dm}^{3}\right)$, Dolom.SA dolomite surface area $\left(\mathrm{m}^{2} / \mathrm{dm}^{3}\right)$, DOC dissolved organic carbon $\left(\mathrm{mmol} / \mathrm{dm}^{3}\right)$

Table 6 RMSE values between observation and simulation values of each output target

\begin{tabular}{lr}
\hline Output target & \multicolumn{1}{l}{ RMSE } \\
\hline Water content & $0.95-1.2\left(\mathrm{~cm}^{3} / \mathrm{cm}^{3}\right)$ \\
Water leachate & $0.13-0.72\left(\mathrm{~cm}^{3} / \mathrm{cm}^{3}\right)$ \\
Salt concentration & $0.21-0.61(\mathrm{mmol} / \mathrm{L})$ \\
\hline
\end{tabular}

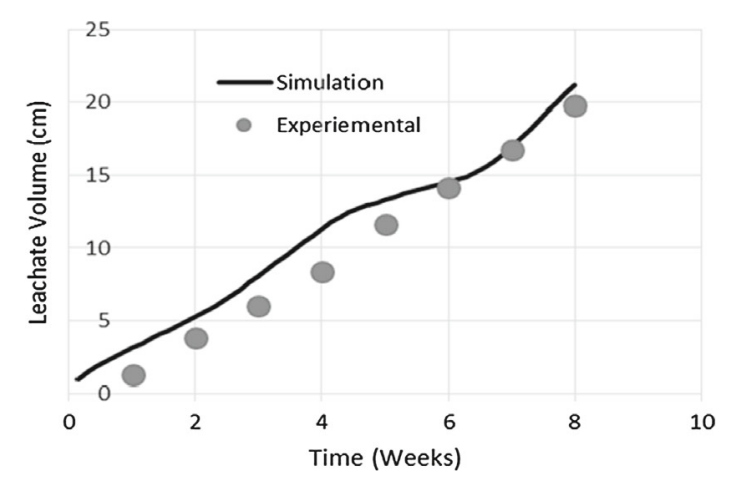

(a)

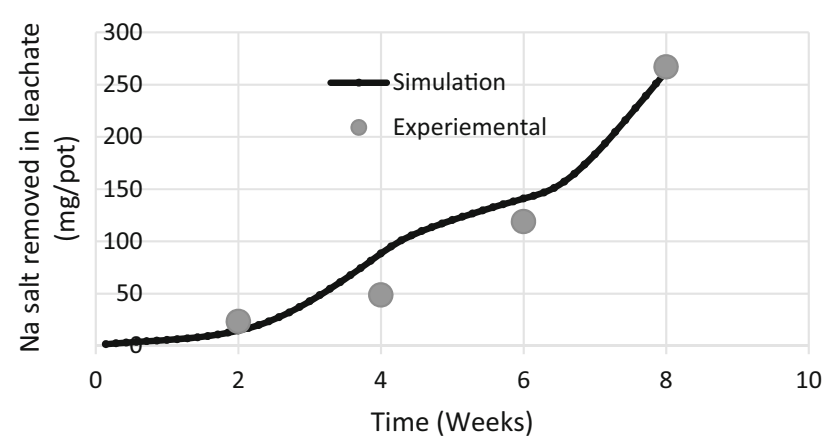

(b)

Fig. 5 Results of model calibration: a leachate volume and b Na salt concentration in the leachate

period. According to data shown in Table 3, rainfall increased from 5.8 to $7.3 \mathrm{~mm} /$ day and evaporation decreased from 4.6 to $4.4 \mathrm{~mm} /$ day. Thus, more water is available for salt washout.

Moreover, noting that the initial $\mathrm{Na}$ concentration is fixed at $6.95 \mathrm{~g} / \mathrm{m}^{2}$, not all of the salts are washed out of the

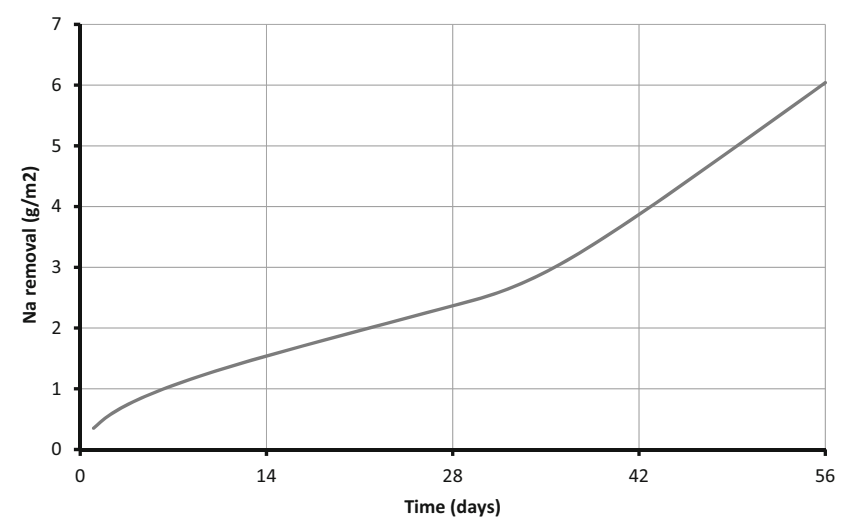

Fig. 6 Simulation of Na removal based on the climate conditions of Burkina Faso

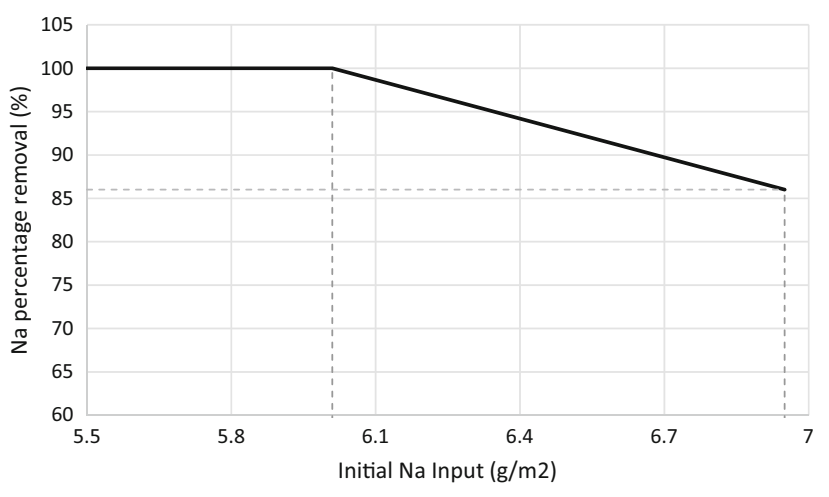

Fig. $7 \mathrm{Na}$ removal percentage versus $\mathrm{Na}$ input

soil after 56 days. Indeed, only $6.01 \mathrm{~g} / \mathrm{m}^{2}$ was removed, and $0.94 \mathrm{~g} / \mathrm{m}^{2}$ remained in the soil.

\section{Impact of the initial Na concentration in the soil}

In this case study, the effect of the initial $\mathrm{Na}$ salt input on salt removal was also investigated. Several runs were performed while varying initial $\mathrm{Na}$ salt concentrations in the top $10 \mathrm{~cm}$ of the soil. The salt removal percentage was determined for each run, as shown in Fig. 7. Figure 7 illustrates the Na removal percentage on the $y$-axis and the amount of salts initially present in the soil. The entire $\mathrm{Na}$ input can be removed if it is initially $6.01 \mathrm{~g} / \mathrm{m}^{2}$ or smaller in the upper layer of the soil. Beyond this value, the excess 
amount will remain in the soil. Therefore, $6.01 \mathrm{~g} / \mathrm{m}^{2}$ can be applied without accumulation, as it is washed out by the rain in the following season.

It is known that the urine volume per person per $24 \mathrm{~h}$ ranges from 800 to $2000 \mathrm{~mL}$ and urine composition varies from person to person depending on several factors. Kawasaki et al. (1982) reported a release of $218 \mathrm{mEq}$ $(5.014 \mathrm{~g})$ sodium salts per person per day. Sene et al. (2013a) adopted the value of $2.84 \mathrm{~g} / \mathrm{L}$ of $\mathrm{Na}$ is urine in his synthetic urine preparations. If we adopt the same value $(2.84 \mathrm{~g} / \mathrm{L})$, it would be possible to apply $2.07 \mathrm{~L}$ of urine without sodium accumulation in soil columns. With respect to nitrogen content in urine, Sene et al. (2013a) adopted the value of $12.05 \mathrm{~g} / \mathrm{L}$. The applied amount of urine can supply $24.84 \mathrm{~g} / \mathrm{m}^{2}$ of nitrogen to the plant. Based on the total nitrogen required to grow Komatsuna $\left(14 \mathrm{~g} / \mathrm{m}^{2}\right)$ recommended by Fujiwara and Narimatsu (2006), the supplied amount of nitrogen exceeded plant's requirement. This suggests that the required amount of nitrogen $\left(14 \mathrm{~g} / \mathrm{m}^{2}\right)$ can be fully met using less urine $(1.16 \mathrm{~L})$ and without salt accumulation in the soil columns. Even though it is difficult to extrapolate these experimental findings to real cases in farmland, it is worth mentioning that Sene et al. (2013b) conclude that adequate application of urine do not lead to salt accumulation.

This analysis investigated the acceptable amount of urine that can be applied sustainably. In cases of extra urine volume use during previous irrigations, the initial salt concentration increases and the excess cannot be washed out, decreasing the removal percentage.

As shown in Fig. 7, the total $\mathrm{Na}$ removal reached $6.01 \mathrm{~g} / \mathrm{m}^{2}$ in 2 months. However, $0.94 \mathrm{~g} / \mathrm{m}^{2}$ of $\mathrm{Na}$ remained in the soil, corresponding to $87 \%$ removal. A $100 \%$ removal is preferable because even small amounts of salts that remain in the soil will deteriorate soils over time. Therefore, and to prevent soil sodication, soil amendment with calcium would be beneficial and improve sodium salt removal. Indeed, sodium ions will be exchanged by calcium ions and the free sodium ions could be washed out from root zone. Hence, in the next paragraph, we study the effect of the calcium supply on the removal of these salts that accumulate in the soil due to the use of urine as a fertilizer.

\section{Impact of Ca supply}

Urine use as a fertilizer may lead to sodic soil conditions due to its high sodium salt content, which can negatively affect plant growth. From chemical analysis performed on soil samples collected at the beginning of the experiment (Table 2), the exchangeable sodium percentage was extremely high $(82 \%)$ confirming the strongly sodic conditions of our soil. Furthermore, and as illustrated above, in the rainy season, Na salts are washed out. It is found that of the $6.95 \mathrm{~g} / \mathrm{m}^{2}$ of Na supplied to the soil, only $6.04 \mathrm{~g} / \mathrm{m}^{2}$ is removed (detected in the leachate). The remaining amount $\left(0.91 \mathrm{~g} / \mathrm{m}^{2}\right)$ remained in the soil. If urine is used each year to fertilize crops, salts will accumulate in the soil. Hence, it is crucial to explore other alternatives that reduce sodium salt accumulation in the soil. One technique used to reclaim these soils is applying a calcium-based soil amendment. In this section, the effect of Ca supply was considered. In this case, we simulated the fates of sodium salts at different depths in the soil column analyzed in the experimental study. A Hoagland solution containing $\mathrm{Ca}$ was added on the 4th and 29th days of the simulation. As Fig. 8 illustrates, the Na concentration in the liquid phase increased suddenly on days 4 and 29 in the upper soil layers (5 and $10 \mathrm{~cm}$ deep). Due to cation exchange with exchangeable $\mathrm{Ca}^{2+}$ in the Hoagland solution, $\mathrm{Na}$ was desorbed from the soil and released into the water (leachate). However, in the deeper layers, i.e., layers 30 and $50 \mathrm{~cm}$ deep, there was no significant peaks, and small $\mathrm{Na}$ concentration increases are observed after some delay (after the remaining Ca reached these layers). Therefore, after desorption, Na might rapidly re-adsorb to soil particles. Thus, increased irrigation or higher rainfall intensity is required to remove $\mathrm{Na}$ by wash out.

As deducted from Sene et al. (2013a) urine application to Kumatsuma cultivation led to an accumulation of $6.95 \mathrm{~g} / \mathrm{m}^{2}$ of $\mathrm{Na}$. To remove this amount of $\mathrm{Na}$ accumulated in the soil, we performed various simulations with various calcium supplies to determine the appropriate calcium supply needed to remove all of the sodium salts from the soil. As Fig. 9 illustrates, higher $\mathrm{Ca}$ supplies desorb larger amounts of $\mathrm{Na}$ from the soil. A supply of $14 \mathrm{~g} / \mathrm{m}^{2}$ of calcium promotes the removal of $6.95 \mathrm{~g} / \mathrm{m}^{2}$ of $\mathrm{Na}$ that accumulated in the soil during previous cultivations. The $6.95 \mathrm{~g} / \mathrm{m}^{2}$ of $\mathrm{Na}$ desorbs from the soil and is detected in the leachate. With the assumption of $2.84 \mathrm{~g} / \mathrm{L}$ of $\mathrm{Na}$ in urine, it follows that the

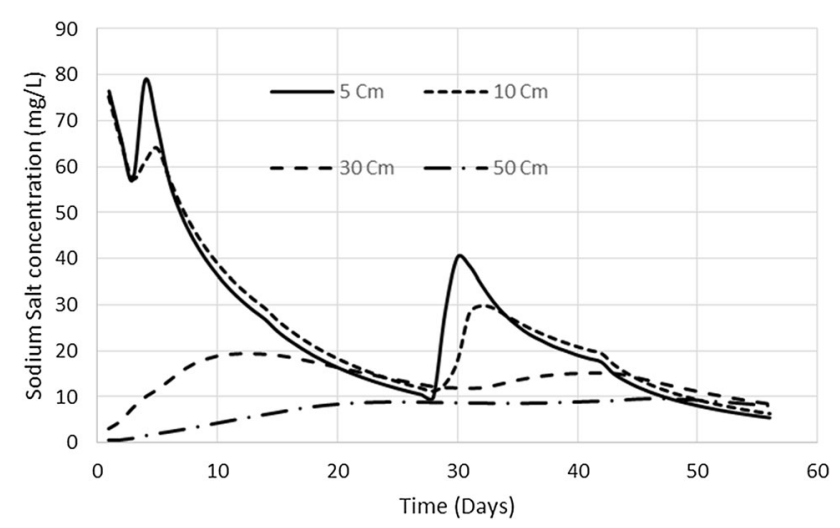

Fig. 8 Na concentration changes at different depths 


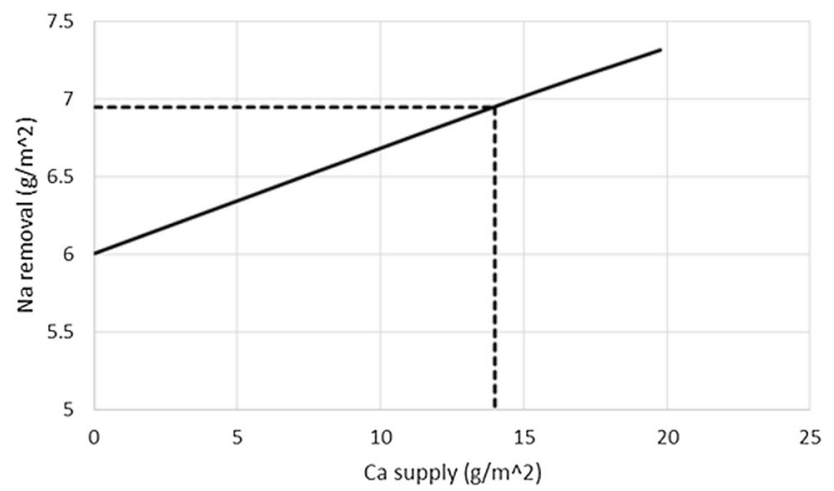

Fig. 9 Na removal versus Ca supply

application of $2.45 \mathrm{~L} / \mathrm{m}^{2}$ of urine along with the supply of $14 \mathrm{~g} / \mathrm{m}^{2}$ of soluble calcium will lead to zero $\mathrm{Na}$ salt accumulation in the soil.

\section{Conclusions}

The removal of salts accumulated in the soil from previous cultivations, assumed to be fertilized with urine, using rainfall and evaporation data from Burkina Faso, with and without plants, was studied. The maximum amount of sodium salts, accumulated from previous cultivations during the dry season, and which can be fully washed out during rainy season was deduced. Experimental findings suggest that in the rainy season, rains will remove a significant amount of the salts that accumulate in the soil during the previous application. Phytoremediation using sorghum, a staple plant in Burkina Faso that was assumed to be a moderately halophytic plant, did not yield satisfactory results and led to salt accumulation in the soil. Indeed, $\mathrm{Na}$ salt washout by rain in non-planted pots was higher than that in planted pots. Simulation data from HYDRUS-1D model, suggests that further improvement of salt washout from soil by rain could be achieved by applying calcium which substituted the sodium in soil. The free sodium was then washed out. A supply of $14 \mathrm{~g} / \mathrm{m}^{2}$ of calcium led to the full washout of salts that accumulated following previous cultivations of Komatsuna fertilized with human urine, supporting the concept of sustainable cultivation using urine.

Acknowledgements The first author gratefully acknowledges financial support from the Japan Society for the Promotion of Sciences (JSPS). He conducted this research when visiting as an International Research Fellow.

\section{Compliance with ethical standards}

Conflict of interest On behalf of all authors, the corresponding author states that there is no conflict of interest.

\section{References}

Adrover M, Farrus E, Moya G, Vadell J (2012) Chemical properties and biological activity in soils of Mallorca following twenty years of treated wastewater irrigation. J Environ Manag 95:188-192

Andersson E (2015) Turning waste into value: using human urine to enrich soils for sustainable food production in Uganda. J Clean Prod 96(1):290-298

Anderson MP, Woessner WW (1991) Applied groundwater modeling: simulation of flow and advective transport, XVIII. Academic press, San Diego, $381 \mathrm{p}$

Chu TW, Shirmohammadi A (2004) Evaluation of the SWAT model's hydrology component in the piedmont physiographic region of Maryland. Trans ASAE 47(4):1057-1073

Cordell D, Drangert JO, White S (2009) The story of phosphorus: global food security and food for thought. Glob Environ Change 19(2):292-305

Corwin DL, Rhoades JD, Šimůnek J (2007) Leaching requirement for soil salinity control: steady-state versus transient models. Agric Water Manag 90:165-180

Dagerskog L, Bonzi M (2010) Opening minds and closing loopsproductive sanitation initiatives in Burkina Faso and Niger. Sustain Sanit Pract 3:4-11

Dikinya O, Areola O (2010) comparative analysis of heavy metal concentration in secondary treated wastewater irrigated soils cultivated by different crops. Int $\mathrm{J}$ Environ Sci Technol $7: 337-346$

FAO (2008) Current world fertilizer trends and outlook to 2011/12. Food and Agriculture Organization of the United Nation, Rome, pp $1-57$

FAO (2009) Current world fertilizer trends and outlook to 2013. Food and Agriculture Organization of the United Nation, Rome, pp 1-14

FAO (2010) State of food insecurity in the world. Food and Agriculture Organization of the United Nations Rome. http:// www.fao.org/docrep/013/i1683e/i1683e.pdff. Accessed 20 Jan 2016

Fujiwara S, Narimatsu J (2006) fertilizing and cultivation of vegetables from property of nutrient absorbance to practical fertilizing method. Rural Culture Association, Tokyo, pp 42-47

Funamizu N (2009) The Concept on wastewater management: "Don't Mix" and "Don't collect" and its application to water management. Science Council Asia, Singapore

Goldstein J (2012) Waste. In: Trentmann F (ed) The Oxford handbook of the history of consumption. Oxford University Press, Oxford, pp 326-347

Gonçalves MC, Šimůnek J, Ramos TB, Martins JC, Neves MJ, Pires FP (2006) Multicomponent solute transport in soil lysimeters irrigated with waters of different quality. Water Resour Res 42:W08401. doi:10.1029/2006WR004802

Hijikata N, Fujii T, Sangare D, Sou M, Ushijima K, Funamizu N (2014) Salts Monitoring and Management for Human Urine Fertilization and Treated Greywater Irrigation in Sub-Sahel Region. J Arid Land Stud 24(1):85-88

Höglund C (2001) Evaluation of microbial health risks associated with the reuse of source separated human urine, $\mathrm{PhD}$ thesis. Royal Institute of Technology (KTH) and Swedish Institute for Infectious Disease Control (SMI), Stockholm

Holliman TR (1998) Reclaimed water distribution and storage. In: Asano $\mathrm{T}$ (ed) Wastewater reclamation and reuse. Technomic Publishing Company Inc, Lancaster, pp 383-436

Inoue M (2012) Salinization status and salt removal techniques. Geotech Eng Mag 60:12-15

Johantigh M (2008) Impact of recycled wastewater irrigation on soil chemical properties in an arid region. Pak J Biol Sci 11:180-187 
Jönsson H,Vinneras B, Höglund C, Stenström TA, Dalhammar G, Kirchmann H (2000) Recycling source seperated human urine (Kallsorterad Humanurin). VA-Forsk Report 2000-1, VAVA $\mathrm{AB}$, Stockholm, Sweden (in Sedish, English summary)

Kawasaki T, Ueno M, Uezono K, Kawazoe N, Nakamuta S, Ueda K, Omae T (1982) Average urinary excretion of sodium in 24 hours can be estimated from a spot-urine specimen. Jpn Circ J 46(9):948-953

Kirchmann H, Pettersson S (1995) Human urine-chemical composition and fertilizer use efficiensy. Fertil Res 40:149-154

McKenzie N, Coughlan K, Cresswell H (2002) Soil physical measurement and interpretation for land evaluation. CSIRO Publishing, Collingwood

Mnkeni PNS, Austin A, Kutu FR (2005) Preliminary studies on the evaluation of human urine as a source of nutrients for vegetables in the Eastern Cape Province, South Africa. In: Proceedings of the 3rd international ecological sanitation conference, Durban, South Africa, 23-26 May, pp 418-426

Mnkeni PNS, Kutu FR, Muchaonyerwa P (2008) Evaluation of human urine as a source of nutrients for selected vegetables and maize under tunnel house conditions in the Eastern Cape, South Africa. Waste Manag Res 26:132-139

Nettling M (1993) Smallholders, householders: farm families and the ecology of intensive, sustainable agriculture. Stanford University Press, Stanford, CA, pp xxii+389

Pradhan SK, Holopainen JK, Weisell J, Heinonen-Tanski H (2010) Human urine and wood ash as plant nutrients for red beet (Beta vulgaris) cultivation: impacts on yield quality. J Agric Food Chem 58:2034-2039

Qadir M, Noble AD, Oster JD, Schubert S, Ghafour A (2005) Driving forces for sodium removal during phytoremediation of calcareous sodic and saline-sodic soils: a review. Soil Use Manag 21:173-180

Ritchie JT (1972) Model for predicting evaporation from a row crop with incomplete cover. Water Resour Res 8:1204-1213

Sene M (2013) Application of human urine as liquid fertilizer in agriculture, Unpublished doctoral thesis. Hokkaido University, Sapporo, Japan
Sene M, Hijikata N, Ushijima K, Funamizu N (2012) Adequate Human urine application pattern for agriculture. Int Res J Agric Sci Soil Sci 2(1):038-045

Sene M, Hijikata N, Ushijima K, Funamizu N (2013a) Effects of continuous application of extra human urine volume on plant and soil. Int J Agric Sci Res 3(3):75-90

Sene M, Hijikata N, Ushijima K, Funamizu N (2013b) Effects of extra human urine volume application in plant and soil. Int J Agric Sci Res 3(6):182-191

Shukla A et al (2014) Soil moisture estimation using gravimetric technique and FDR probe technique: a comparative analysis. Am Int J Res Form Appl Nat Sci 8(1):89-92

Šimůnek J, Hopmans JW (2009) Modeling compensated root water and nutrient uptake. Ecol Model 220(4):505-521

Šimůnek J, van Genuchten MT, Šejna M (2008) Development and applications of the HYDRUS and STANMOD software packages, and related codes. Vadose Zone J 7:587-600

Singh J, Knapp HV, Demissie M (2004) Hydrologic modelling of the Iroquois River watershed using HSPF and SWAT, ISWS CR 2004-08

Tanaka U. (2005) Significance of soil management practices on degradation and/or conservation of upland sandy soils in semiarid West Africa. FAO-UN conference on Management of Tropical Sandy Soils for Sustainable Agriculture, Khon Kaen, Thailand, 27th November to 2nd December

US Salinity Laboratory Staff (1954) Diagnosis and improvement of saline and alkali soils. USDA Agric. Handb. No. 60. US Government Printing Office, Washington, DC

Ushijima K, Funamizu N, Nabeshimab T, Hijikata N, Ito R, Souc M, Maïgc AH, Sintawardani N (2015) The postmodern sanitation: agro-sanitation business model as a new policy. Water Policy 17(2):283-298

Vassilev SV, Baxter D, Andersen LK, Vassileva CG (2010) An overview of the chemical composition of biomass. Fuel. 89(5):913-933

Vazquez-Amábile GG, Engel BA (2005) Use of SWAT to compute groundwater table depth and stream flow in the Muscatatuck River watershed. Trans ASAE 48(3):991-1003 